\title{
Velocity control of a two-wheeled inverted pendulum mobile robot: a fuzzy model-based approach
}

\author{
Mustapha Muhammad ${ }^{1}$, Amir A. Bature ${ }^{2}$, Umar Zangina ${ }^{3}$, Salinda Buyamin ${ }^{4}$, Anita Ahmad ${ }^{5}$, \\ Mohamad A. Shamsudin 6 \\ ${ }^{1,2}$ Department of Mechtronics Engineering, Bayero University, Kano, Nigeria \\ ${ }^{3,4,5,6}$ School of Electrical Engineering, Faculty of Engineering, Unversiti Teknologi Malaysia, Malaysia
}

\begin{tabular}{l} 
Article Info \\
\hline Article history: \\
Received Mar 23, 2019 \\
Revised May 25, 2019 \\
Accepted May 30, 2019 \\
\hline Keywords: \\
Fuzzy Lyapunov function \\
Linear matrix inequality (LMI) \\
Mobile robot \\
T-S fuzzy model \\
TWIP
\end{tabular}

TWIP

\begin{abstract}
This paper presents the design of a fuzzy tracking controller for balancing and velocity control of a Two-Wheeled Inverted Pendulum (TWIP) mobile robot based on its Takagi-Sugino (T-S) fuzzy model, fuzzy Lyapunov function and non-parallel distributed compensation (non-PDC) control law. The T-S fuzzy model of the TWIP mobile robot was developed from its nonlinear dynamical equations of motion. Stabilization conditions in a form of linear matrix inequalities (LMIs) were derived based on the T-S fuzzy model of the TWIP mobile robot, a fuzzy Lyapunov function and a non-PDC control law. Based on the derived stabilization conditions and the T-S fuzzy model of the TWIP mobile robot, a state feedback velocity tracking controller was then proposed for the TWIP mobile robot. The balancing and velocity tracking performance of the proposed controller was investigated via simulations. The simulation result shows the effectiveness of the proposed control scheme.
\end{abstract}

Copyright () 2019 Institute of Advanced Engineering and Science. All rights reserved.

\section{Corresponding Author:}

Salinda Buyamin,

School of Electrical Engineering, Faculty of Engineering,

Unversiti Teknologi Malaysia (UTM),

81310 UTM Johor Bahru, Malaysia

Email:salinda@utm.my

\section{INTRODUCTION}

A two-wheeled inverted pendulum (TWIP) mobile robot is a three-degree-of-freedom underactuated mechanical system with highly nonlinear dynamics. It is quiet challenging to control such system due to its unstable and under-actuated nature. Numerous works on modeling and control of TWIP mobile robot have been presented in literature. Kim et al [1] investigated the exact dynamics of the TWIP mobile robot, and a Linear Quadratic Regulator (LQR) controller was developed for balancing the robot. Fiacchini et al [2] proposed linear and nonlinear controllers for stabilizing a personal pendulum vehicle. To compensate for the measurable disturbances, the work in [3] compared the performance of Model Predictive Controller and LQR. Multipoint pole placement control for velocity tracking of the TWIP is shown in [4]. In Jones and Stol [5], the performance of the two wheeled mobile robot in low-traction environment was investigated by designing a LQR controller based on linearized model of the robot which includes wheel slip effects. Pathak et al [6] proposed velocity and position controllers for the TWIP robot via partial feedback linearization. Dai et al [7] proposed sliding mode controllers for self-balancing and yaw motion and designed independently. While Kim et al [8] investigated a nonlinear motion control using the State-Dependent Riccati Equation (SDRE) control framework. Kharola et al [9] discussed a fuzzy logic control strategy for control and stabilization of TWIP.

Most of the controllers mentioned above are model-based, which can be classified as either linear or nonlinear controllers. Mostly linear controllers are simple to design and easy to implement, but the 
performance level is limited due to approximations, while most of nonlinear controllers performed better but are complex to design and difficult to implement. Using T-S fuzzy model-based control, it is possible to combine the advantages of both linear and nonlinear controllers (i.e. simplicity and better performance). A T-S fuzzy model can effectively represent the system dynamics of a nonlinear system such as TWIP mobile robot using linear rule consequence, which makes it easier to apply linear control techniques in the analysis and control synthesis for the system. Numerous works on the stability analysis and control synthesis of T-S fuzzy model-based control systems have been reported in literature [10-12].

This paper applies the T-S fuzzy technique to design a fuzzy tracking controller for balancing and velocity control of a TWIP mobile robot. The controller design is based on a fuzzy Lyapunov function and a non-PDC control law. The main contribution of this paper is the development of a fuzzy model based state feedback control scheme, which guarantees global stability and provides desired transient behavior for T-S fuzzy model-based controlsystems, based on which a fuzzy model-based tracking controller for the balancing and velocity tracking control of a TWIP mobile robot is developed.

The rest of the paper is organized as follows: In Section two the dynamic model of the TWIP mobile robot is presented. Section three presents the fuzzy modeling of the TWIP mobile robot, whereas section four presents the fuzzy controller synthesis. The velocity tracking controller design is presented in section five. In section six the simulation results are presented and finally the conclusion is made in section seven.

\section{DYNAMIC MODEL OF THE TWIP MOBILE ROBOT}

The model considered in this paper is based on the TWIP mobile robot presented in [6]. Using Kane's method, the dynamical equations of motion of the TWIP mobile robot can be obtained [13-15]. Using the parameters in Table 1, the numerical model of the TWIP mobile robot is obtained as in (1)-(3):

Table 1. TWIP mobile robot parameters and variables

\begin{tabular}{|c|c|c|c|}
\hline Symbol & Parameter/Variables & Value & Unit \\
\hline$m_{B}$ & Mass of the main body of the TWIP mobile robot & 35 & $\mathrm{~kg}$ \\
\hline$m_{W}$ & Mass of each wheel & 5 & $\mathrm{Kg}$ \\
\hline$L$ & Half of the distance between the wheels & 0.20 & 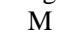 \\
\hline$R$ & Radius of each wheel & 0.25 & M \\
\hline$I_{2}$ & The moment of inertia of the body about $\boldsymbol{n}_{2}$ direction & 0.649 & $\mathrm{kgm}^{2}$ \\
\hline$I_{3}$ & The moment of inertia of the body about $\boldsymbol{n}_{3}$ direction & 1.829 & $\mathrm{kgm}^{2}$ \\
\hline$g$ & Gravitational acceleration & 9.81 & $\mathrm{~m} / \mathrm{s}^{2}$ \\
\hline$d$ & Distance between the center of the wheels axis $C$ and the center of gravity $G$ & 0.25 & M \\
\hline$\phi$ & Dendulum tilt angle & & $\operatorname{Rad}$ \\
\hline$\psi$ & Yaw angle (orientation of the robot) & & $\operatorname{Rad}$ \\
\hline$x$ & TWIP mobile robot position & & M \\
\hline
\end{tabular}

$$
\begin{aligned}
& \ddot{x}=\frac{\left(0.25 \cos ^{2} \phi-0.4583\right) \sin \phi}{\left(\cos ^{2} \phi-2.619\right)} \dot{\psi}^{2}+\frac{9.81 \sin \phi \cos \phi}{\left(\cos ^{2} \phi-2.619\right)}-\frac{0.4583 \sin \phi}{\left(\cos ^{2} \phi-2.619\right)} \dot{\phi}^{2} \\
& +\frac{0.1143 \cos \phi+0.2095}{\left(\cos ^{2} \phi-2.619\right)}\left(\tau_{1}+\tau_{2}\right) \\
& \ddot{\psi}=-\frac{\sin \phi \cos \phi}{\left(\sin ^{2} \phi+0.6424\right)} \dot{\psi} \dot{\phi}-\frac{0.3657}{\left(\sin ^{2} \phi+0.6424\right)}\left(\tau_{1}-\tau_{2}\right) \\
& \ddot{\phi}=-\frac{0.4286 \sin \phi \cos \phi}{\left(\cos ^{2} \phi-2.619\right)} \dot{\psi}^{2}-\frac{56.0571 \sin \phi}{\left(\cos ^{2} \phi-2.619\right)}+\frac{\sin \phi \cos \phi}{\left(\cos ^{2} \phi-2.619\right)} \dot{\phi}^{2}-\frac{0.4571 \cos \phi+0.6531}{\left(\cos ^{2} \phi-2.619\right)}\left(\tau_{1}+\tau_{2}\right)
\end{aligned}
$$

\section{T-S FUZZY MODEL}

A T-S fuzzy model as proposed by Takagi and Sugeno [16] describes the nonlinear system by a set of IF THEN rules with fuzzy sets as antecedents and linear models as the consequents. The overall fuzzy model can then be obtained by fuzzy blending of the linear models. The $i^{\text {th }}$ rule of the T-S fuzzy model as described in [17] and the final outputs of the fuzzy systems are inferred as follows: 


$$
\left\{\begin{array}{l}
\dot{x}(t)=\frac{\sum_{i=1}^{q} \omega_{i}(z(t))\left\{A_{i} x(t)+B_{i} u(t)\right\}}{\sum_{i=1}^{q} \omega_{i}(z(t))} \\
y(t)=\frac{\sum_{i=1}^{q} \omega_{i}(z(t)) C_{i} x(t)}{\sum_{i=1}^{q} \omega_{i}(z(t))}
\end{array}\right.
$$

where:

$$
\begin{aligned}
& z(t)=\left[z_{1}(t), \ldots \ldots ., z_{n}(t)\right] \\
& \omega_{i}(z(t))=\prod_{j=1}^{n} M_{i j}\left(z_{j}(t)\right)
\end{aligned}
$$

The term $M_{i j}\left(z_{j}(t)\right)$ is the grade of the membership function of $z_{j}(t)$ in $M_{i j}$.

\subsection{T-S fuzzy model of TWIP mobile robot}

This fuzzy model considered in this paper is based on the T-S fuzzy model of the TWIP mobile robot developed in [18], which is derived from nonlinear dynamical model of the TWIP mobile robot in (1)-(3). It has been proven that the orientation of the TWIP is independent of the dynamics of the system [13], it depends on the external input; hence $\dot{\psi}=0$. Therefore (1)-(3) can be written as in (7)-(9):

$$
\begin{aligned}
& \ddot{x}=\frac{9.81 \sin \phi \cos \phi}{\left(\cos ^{2} \phi-2.619\right)}-\frac{0.4583 \sin \phi}{\left(\cos ^{2} \phi-2.619\right)} \dot{\phi}^{2}+\frac{0.1143 \cos \phi+0.2095}{\left(\cos ^{2} \phi-2.619\right)}\left(\tau_{1}+\tau_{2}\right) \\
& \ddot{\psi}=-\frac{0.3657}{\left(\sin ^{2} \phi+0.6424\right)}\left(\tau_{1}-\tau_{2}\right) \\
& \ddot{\phi}=-\frac{56.0571 \sin \phi}{\left(\cos ^{2} \phi-2.619\right)}+\frac{\sin \phi \cos \phi}{\left(\cos ^{2} \phi-2.619\right)} \dot{\phi}^{2}-\frac{0.4571 \cos \phi+0.6531}{\left(\cos ^{2} \phi-2.619\right)}\left(\tau_{1}+\tau_{2}\right)
\end{aligned}
$$

From the dynamical (7) and (9), the state variables that makes the system nonlinear are $\phi$ and $\dot{\phi}$. Therefore, the premise variables are:

$$
z(t)=\left[\begin{array}{ll}
\phi & \dot{\phi}
\end{array}\right]^{\mathbf{T}}
$$

From expert knowledge $\phi \in\left[\begin{array}{ll}0 & \pi / 2\end{array}\right]$ and $\dot{\phi} \in\left[\begin{array}{ll}0 & 6\end{array}\right]$ [18-20]. The following operating points were chosen for the tilt angle $\phi: 0, \pi / 18, \pi / 9, \pi / 6,2 \pi / 9,5 \pi / 18, \pi / 3$. Based on the selected operating points the 14 T-S fuzzy rules are formulated.

\subsection{T-S fuzzy controoller design}

The fuzzy controller design is based on the following non-PDC control law, which is proposed

$$
u(t)=N_{z} P_{z}^{-1} x(t)
$$

where: $N_{z}=\sum_{i=1}^{q} \alpha_{i}(z(t)) N_{i}$

The following fuzzy Lyapunov function is also considered in the design [17]: 


$$
V(x(t))=x(t)^{T} P_{z}^{-1} x(t)
$$

where:

$$
P_{z}=\sum_{i=1}^{r} \alpha_{i}(z(t)) P_{i}, P_{i}=P_{i}^{T}>0
$$

The closed-loop system based on the non-PDC control law [11] and the T-S fuzzy model is as follows:

$$
\dot{x}(t)=\left(A_{z}+B_{z} N_{z} P_{z}^{-1}\right) x(t)
$$

The controller design is based on the assumption that the premise variables vector and the state variables vector are related as follows:

$$
z(t)=T x(t)
$$

where $T \in \mathbf{R}^{n \times 1}$ is a diagonal matrix

The following requirement are considered in the fuzzy controller design:

- Stabilization: This is aimed at designing a controller such that the closed-loop system in (14) is asymptotically stable.

- Pole Placement: This is aimed at designing a controller such that the poles of the closed-loop system in (14) are located in a prescribed sub-region of the complex left-half plane, so as to achieve a desired transient behavior.

Remark 1 [19-21]. The second requirement is fundamentally related to the linearized subsystems that comprise the given (nonlinear) system. For this reason, the actual performance will be an approximation of the expected based on the design strategy outlined above.

\subsection{LMI formulation for stabilization}

The time derivative of the fuzzy Lyapunov function in Equation (13) along the trajectories of the T-S fuzzy model is obtained as:

$$
\dot{V}(x(t))=\dot{x}(t)^{T} P_{z}^{-1} x(t)+x(t)^{T} \dot{P}_{z}^{-1} x(t)+x(t)^{T} P_{z}^{-1} \dot{x}(t)<0
$$

Based on the derivation, the LMIs can be written as [20-25]:

$$
\begin{aligned}
& \sum_{i=1}^{q} \alpha_{i}^{2}(z(t)) \bar{\Gamma}_{i i}+\sum_{i=1}^{q} \sum_{j>i} \alpha_{i}(z(t)) \alpha_{j}(z(t))\left\{\bar{\Gamma}_{i j}+\bar{\Gamma}_{j i}\right\}<0 \\
& \sum_{i=1}^{q} \alpha_{i}^{2}(z(t)) \bar{\Lambda}_{i i}+\sum_{i=1}^{q} \sum_{j>i} \alpha_{i}(z(t)) \alpha_{j}(z(t))\left\{\bar{\Lambda}_{i j}+\bar{\Lambda}_{j i}\right\}>0
\end{aligned}
$$

where:

$$
\begin{aligned}
& \bar{\Gamma}_{i j}=A_{i} P_{j}+P_{j} A_{i}^{T}+B_{i} N_{j}+N_{j}^{T} B_{i}^{T} \\
& \bar{\Lambda}_{i j}=T A_{i} P_{j}+T B_{i} N_{j}+P_{j}^{T}\left(T A_{i}\right)+N_{j}^{T}\left(T B_{i}\right)+\lambda I
\end{aligned}
$$

\subsection{LMI formulation for pole-placement constraint}

Stabilization alone is not enough to give satisfactory transient performance. Therefore, to get satisfactory transient response of the closed loop system, the closed loop poles have to be placed in a prescribed sub-region (LMI region) of the complex left half plane. LMI regions are subset of the complex plane, which are convex and symmetrical with respect to real axis [20-23]. In this work, the LMI region in Figure 1, which is the intersection of disc centered at origin with radius $r$ and a conic sector with apex at origin and inner angle $2 \theta$, is considered for placing the closed loop poles. Consider the following linear dynamic system and the common quadratic Lyapunov function respectively:

Velocity control of a two-wheeled inverted pendulum mobile robot: a fuzzy model... (Salinda Buyamin) 


$$
\begin{aligned}
& \dot{x}(t)=A x(t) \\
& V(x)=x(t)^{\mathbf{T}} P x(t), P=P^{\mathbf{T}}>0
\end{aligned}
$$

According to Chilali and Gahinet Theorems [19] the system in Equation (21) based on the Lyapunov functions in Equation (22) is D stable (all the poles of the system lie in the LMI region of Figure 1, if and only if there exist a symmetrical positive definite matrix $P$. The Theorems in [19] were extended to fuzzy control systems in [23-27] .

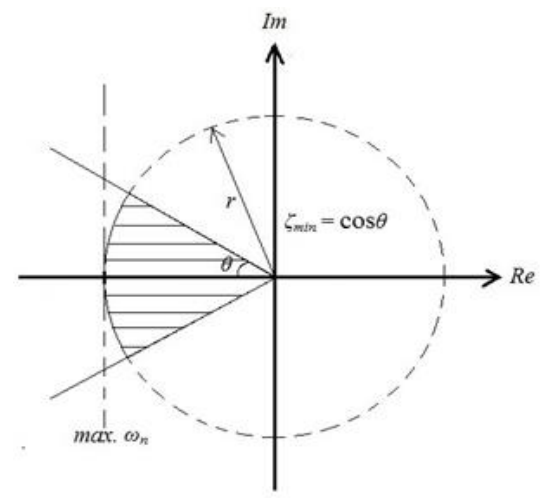

Figure 1. LMI region (D) for pole placement

Remark 2 [22]. The D-stability constraints are applied to the local subsystems, not to the global system, therefore, the locally-available Lyapunov functions can be used which are independent of the proposed fuzzy Lyapunov function because there can exist many Lyapunov function showing the stability of the subsystems. The $i$ th local subsystem of the closed-loop T-S fuzzy model [14] can be written as:

$$
\dot{x}(t)=\left(A_{i}+B_{i} N_{i} P_{i}^{-1}\right) x(t)
$$

Consider the following local quadratic Lyapunov function:

$$
V(x)=x(t)^{\mathbf{T}} P_{i} x(t)
$$

Hence, using the local quadratic Lyapunov function in Equation (24) and the concept of D-stability presented, the constraint to place the poles of the $i$ th subsystem in Equation (23) in the LMI region of Figure 1 can be expressed in terms of LMIs as:

$$
\begin{aligned}
& {\left[\begin{array}{cc}
-r P_{i} & \Lambda_{i i} \\
\Lambda_{i i}^{\mathbf{T}} & -r P_{i}
\end{array}\right]<0} \\
& {\left[\begin{array}{cc}
\sin \theta\left(\Lambda_{i i}+\Lambda_{i i}^{\mathbf{T}}\right) & \cos \theta\left(\Lambda_{i i}-\Lambda_{i i}^{\mathbf{T}}\right) \\
\cos \theta\left(\Lambda_{i i}^{\mathbf{T}}-\Lambda_{i i}\right) & \sin \theta\left(\Lambda_{i i}+\Lambda_{i i}^{\mathbf{T}}\right)
\end{array}\right]<0}
\end{aligned}
$$

where:

$$
\Lambda_{i i}=A_{i} P_{i}+B_{i} N_{i} ; \Lambda_{i i}^{\mathbf{T}}=P_{i} A_{i}^{\mathbf{T}}+N_{i}^{T} B_{i}^{\mathbf{T}}
$$

From the results obtained the following theorem can be established:

Theorem 2: The closed-loop fuzzy model based system (14) is D-Stable (all the poles of the subsystems of system (14) lie in the LMI region of Figure 1 if there exist matrices $\left\{P_{i}=P_{i}^{T}>0\right\}_{i=1}^{q}$ and $\left\{N_{i}\right\}_{i=1}^{q}$ satisfying the following LMI's: 


$$
\begin{aligned}
& {\left[\begin{array}{cc}
-r P_{i} & \Lambda_{i i} \\
\Lambda_{i i}^{\mathrm{T}} & -r P_{i}
\end{array}\right]<0 \quad i=1,2, \ldots \ldots, q} \\
& {\left[\begin{array}{cc}
\sin \theta\left(\Lambda_{i i}+\Lambda_{i i}^{\mathrm{T}}\right) & \cos \theta\left(\Lambda_{i i}-\Lambda_{i i}^{\mathrm{T}}\right) \\
\cos \theta\left(\Lambda_{i i}^{\mathrm{T}}-\Lambda_{i i}\right) & \sin \theta\left(\Lambda_{i i}+\Lambda_{i i}^{\mathrm{T}}\right)
\end{array}\right]<0 \quad i=1,2, \ldots \ldots, q}
\end{aligned}
$$

Remark 3 [19]. The D-stability constraints are usually used as supplementary constraints, hence constraints of the LMI region to both cases $i=j$ and $i<j$ may not be necessary: it suffices to locate the poles of the dominant terms (in the case of $i=j$ ) in the prescribed LMI regions.

\subsection{Fuzzy state feedback controller synthesis}

The synthesis of fuzzy state feedback control system that guarantees stability and satisfies additional constraints on the closed-loop pole location is considered. Combining Theorems 1 and 2 results in Theorem 3 , which provides LMI formulation of fuzzy state feedback synthesis that ensures global stability and gives desired transient behavior.

Theorem 3: The fuzzy model based system in Equation (14) can be stabilized by the non-PDC controller in (11) with all the poles of the subsystems of the closed-loop system located in the LMI region of Figure 1, if there exist a scalar $\lambda>0$, and matrices $\left\{P_{i}=P_{i}^{T}>0\right\}_{i=1}^{q}$ and $\left\{N_{i}\right\}_{i=1}^{q}$.

\section{FUZZY TRACKING CONTROLLER DESIGN}

This is a state feedback tracking controller which is based on the fuzzy state feedback control law in Equation (19). It consists of the stabilization part and the tracking part. The block diagram of the tracking control system is shown in Figure 2, where $x(t)$ is the state vector, $u(t)$ is the control input vector, $r(t)$ is the reference input vector and $y(t)$ is the output vector. The velocity tracking control law used is:

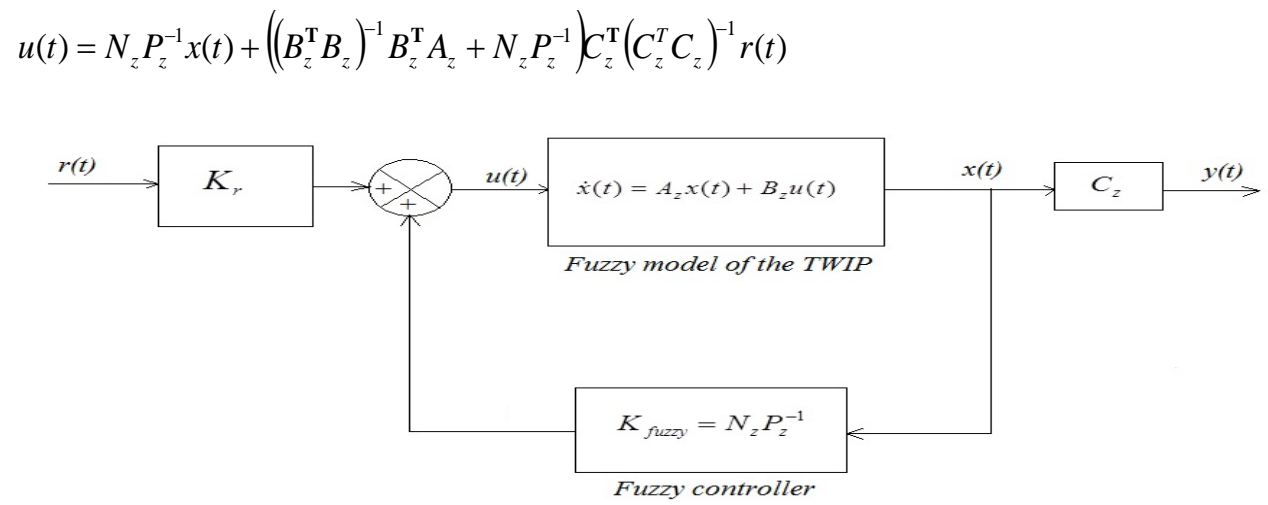

Figure 2. Tracking control system

\section{SIMULATION}

To investigate the balancing and tracking performance of the proposed controller, simulations were carried out. The TWIP is required to balance itself and track a reference velocity. The parameter settings are shown in Table 2 while the tilt angle, velocity and orientation responses under step command are shown in Tables 3, 4 and 5 respectively.

Table 2. Parameter settings for simulation condition

\begin{tabular}{cc}
\hline Condition/Parameter & Condition \\
\hline Desired velocity $(\mathrm{m} / \mathrm{s})$ & 2 \\
Initial velocity $(\mathrm{m} / \mathrm{s})$ & 0 \\
Desired tilt angle $(\mathrm{rad})$ & 0 \\
Initial tilt angle $(\mathrm{rad})$ & $\pi / 6$ \\
Desired orientation $(\mathrm{rad})$ & $\pi / 6$ \\
Initial orientation $(\mathrm{rad})$ & 0 \\
\hline
\end{tabular}


Table 3. Tilt angle response under step command

\begin{tabular}{ccc}
\hline Controller & $\begin{array}{c}\text { Settling } \\
\text { time }(\mathrm{s})\end{array}$ & $\begin{array}{c}\text { Overshoot } \\
(\%)\end{array}$ \\
\hline Fuzzy & 3.4 & 0 \\
Nonlinear & 12.5 & 19 \\
\hline
\end{tabular}

Table 4. Velocity response under step command

\begin{tabular}{ccc}
\hline Controller & $\begin{array}{c}\text { Settling } \\
\text { time }(\mathrm{s})\end{array}$ & $\begin{array}{c}\text { Overshoot } \\
(\%)\end{array}$ \\
\hline Fuzzy & 3.8 & 0 \\
Nonlinear & 12.5 & 32.7 \\
\hline
\end{tabular}

Table 5. Orientation response under step command

\begin{tabular}{ccc}
\hline Controller & $\begin{array}{c}\text { Settling } \\
\text { time }(\mathrm{s})\end{array}$ & $\begin{array}{c}\text { Overshoot } \\
(\%)\end{array}$ \\
\hline Fuzzy & 4.2 & 0 \\
Nonlinear & 1.4 & 45.72 \\
\hline
\end{tabular}

Based on the simulation results shown in Figures 3-5, settling times of 3.4, 3.8 and 4.2 seconds for the tilt angle, velocity response and robot orientation respectively using the fuzzy controller have been recorded. The non-liner controller shows a lagging 12.5 seconds for both the tilt angle and the velocity response which indicated the superior performance of the fuzzy controller over the non-linear controller in that region. For the robot orientation a settling time of 1.4 seconds results using the non-linear controller while the fuzzy controller lags with $4.2 \mathrm{sec}$, thus, showing the superior performance of the non-linear controller over the fuzzy. No overshoots were recorded for all the cases using the fuzzy controller as against overshoots of 19, 32.7 and 45.72 observed with the non-linear controller. Conclusively, the fuzzy controller also shows a marked stability as shown in all the Figures 3-7 with no oscillatory responses while the nonlinear controller indicated some oscillations.

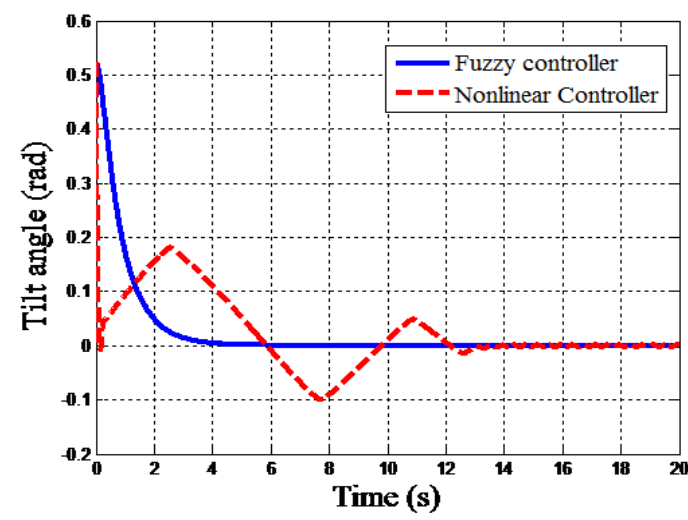

Figure 3. Tilt angle response under step command

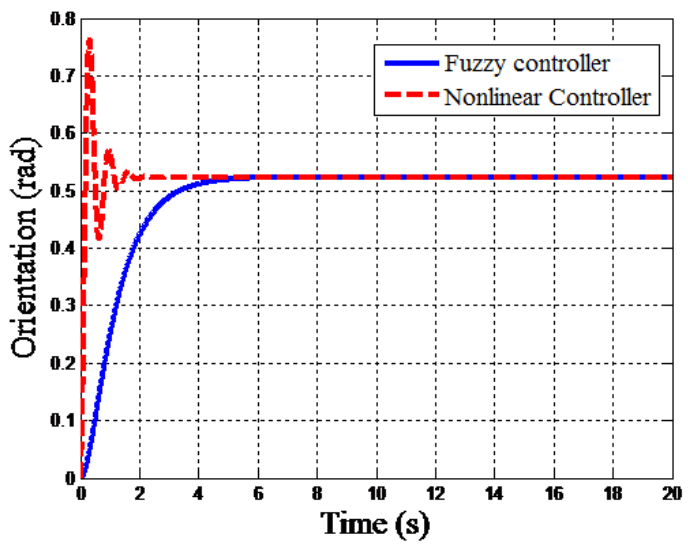

Figure 5. Robot orientation under step command

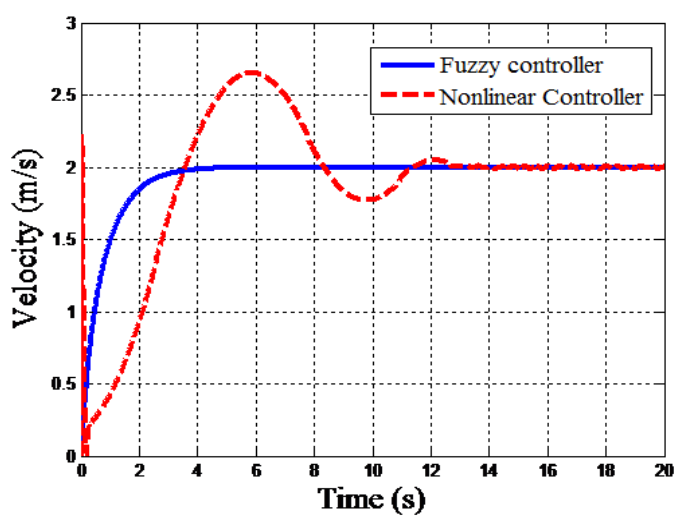

Figure 4. Velocity response under step command

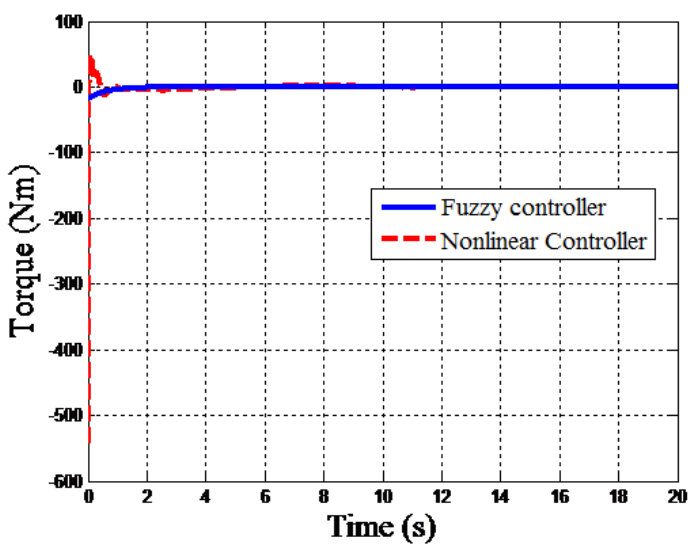

Figure 6. Control input for wheel 1 under step command 


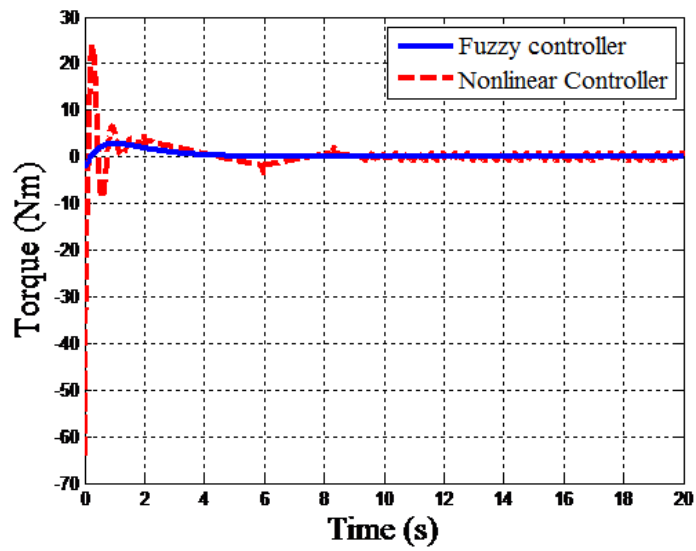

Figure 7. Control input for wheel 2 under step command

\section{CONCLUSION}

The T-S fuzzy model of the TWIP mobile robot was developed from its nonlinear dynamical equations of motion using 14 fuzzy rules. Based on continous T-S fuzzy model, stabilization conditions with constraints on the closed-loop poles location were established in the form of linear matrix inequalities. The established stabilization conditions guaranteed the stability of the system and gives desired transient behavior. Based on the developed T-S fuzzy model and the established stabilization conditions, a velocity tracking controller was proposed for the balancing and velocity tracking of the TWIP mobile robot. The balancing and tracking performance of the proposed controller was investigated via simulation, and the results were compared with those from a nonlinear controller. The results show that the controller was able to track a reference velocity while keeping the TWIP mobile robot balanced. The results also demonstrate that, the proposed controller gives better transient performance and require less controlled input signal compared to the nonlinear controller

\section{ACKNOWLEDGEMENTS}

Special thanks to the Ministry of Higher Education Malaysia (MOHE), Universiti Teknologi Malaysia for the financial support (Q. J130000.2523.17H45), facilities and infrastructure, and great appreciation to Bayero University, Kano for the sponsorship.

\section{REFERENCES}

[1] Kim, S.H. Kim, and Y.K. Kwak, "Dynamic analysis of a nonholonomic two-wheeled inverted pendulum robot".Journal of Intelligent and Robotic Systems: Theory and Applications, 44: p. 25-46, 2005.

[2] M. Fiacchini, et al., Design and Experimentation of a Personal Pendulum Vehicle, in Proceedings of the 7th Portuguese Conference on Automation Control (CONTROLO'06), Lisbon. p. 1-6.2006.

[3] N. Minouchehr and S.K. Hosseini-Sani, "Design of Model Predictive Control of two-wheeled inverted pendulum robot. in 20153 rd RSI International Conference on Robotics and Mechatronics (ICROM). p.12-17. 2015

[4] M.Muhammad, et al., "Multiple Operating Points Model-Based Control of a Two-Wheeled Inverted Pendulum Mobile Robot. International Journal of Mechanical \& Mechatronics Engineering, 13(5): p. 1-9. 2013.

[5] D.R. Jones, and K.a. Stol, "Modelling and Stability Control of Two-Wheeled Robots in Low-Traction Environments, in Australasian Conference on Robotics and Automation (ACRA). p. 1-9.2010

[6] K. Pathak, J. Franch, and S.K. Agrawal, "Velocity and Position Control of a Wheeled Inverted Pendulum by Partial Feedback Linearization". IEEE Transactions on Robotics, 21: p. 505-513,2015.

[7] F. Dai, et.al. "A two-wheeled inverted pendulum with Friction compensation" ScienceDirect journal of Mechatronics. Volume 30, Pages 116-125 September 2015,

[8] S. Kim, and S. Kwon, "Nonlinear Optimal Control Design for Underactuated Two-Wheeled Inverted Pendulum Mobile Platform" IEEE/ASME Transactions on Mechatronics, 22(6): p. 2803-2808.2017

[9] A. Kharola, "The control of two-wheeled inverted pendulum robot (TWIPR) using fuzzy logic". in 2015 IEEE International Conference on Computational Intelligence and Computing Research (ICCIC). P 21-27. 2015.

[10] N. Jamin, and N. Abdul Ghani "Two-Wheeled Wheelchair Stabilization Control Using Fuzzy Logic Controller Based Particle Swarm Optimization" IEEE International Conference on Automatic Control and Intelligent Systems p 78-83. 2016.

[11] S. Fekih, B. Sfaihi, and M. Benrejeb. "T-S fuzzy nonlinear discrete-time models stability conditions based on vector norms". in 2017 International Conference on Advanced Systems and Electric Technologies (IC_ASET).

Velocity control of a two-wheeled inverted pendulum mobile robot: a fuzzy model... (Salinda Buyamin) 
[12] R. Raj and B.M. Mohan. "Modelling and analysis of a general Takagi-Sugeno fuzzy PI/PD controller with modified rule base” in 2016 IEEE Students\&\#8217; Technology Symposium (TechSym). 2016

[13] J. Huang, et.al., "non linear disturbance observer-based dynamic surface control of mobile wheeled inverted pendulum” IEEE Trans. Control Syst. Technol., vol. 23, no. 6, pp. 2400-2407, Nov. 2015

[14] Z. Xiu, H. Zhang, and J. Mao. A systematic design approach of TS-PID Fuzzy Controllers. in Proceeding of the 11th World Congress on Intelligent Control and Automation. 2014.

[15] M. Muhammad, et al., "Dynamic modeling and analysis of a two-wheeled inverted pendulum robot". in Proceedings - CIMSim 2011: 3rd International Conference on Computational Intelligence. P 7-12.2011

[16] T. Takagi, and M. Sugeno, "Fuzzy identification of systems and its applications to modeling and control". IEEE Transactions on Systems, Man and Cybernetics, 15: p. 116-132.1985

[17] M. Muhammad et al., "Velocity Tracking Control of a Two-Wheeled Inverted Pendulum Robot: a Comparative Assessment between Partial Feedback Linearization and LQR Control Schemes". International Review on Modeling and Simulations, 5 P. 1754-1762. 2012.

[18] S Ming, S. Wang, and J. Z. Sun "Simultaneous balancing and trajectory tracking control for two-wheeled inverted pendulum vehicles: a composite control approach" Scince Direct Journal of Neuro-computing Vol.191, P. 44-54. 2016

[19] N. S. Bhangal, "Design and Performance of LQR and LQR based Fuzzy Controller for Double Inverted Pendulum System" Journal of Image and Graphics. Vol. 1, No. 3, p. 143-146.2013

[20] M. Muhammad, et al., "Takagi-Sugeno Fuzzy Control of a Two Wheeled Inverted Pendulum Mobile Robot" in International conference on Automation and Control Engineering. p. 1754-1762.2012

[21] K. Tanaka, H. Ohtake, and H.O. Wang, "A Descriptor System Approach to Fuzzy Control System Design via Fuzzy Lyapunov Functions”. IEEE Transactions on Fuzzy Systems, 15: p. 333-341.2007

[22] M. Muhammad, et al., "Takagi-Sugeno fuzzy modeling of a two-wheeled inverted pendulum robot". Journal of Intelligent and Fuzzy Systems, 25: p. 535-546. 2013

[23] S.K. Hong, and R. Langari, "An LMI based H infinity fuzzy control system design with TS framework. Information Sciences". 123: p. 163-179. 2000

[24] J.Li, S. Zhou, and S. Xu, "Fuzzy control system design via fuzzy Lyapunov functions". IEEE transactions on systems, man, and cybernetics. Part B, Cybernetics: a publication of the IEEE Systems, Man, and Cybernetics Society. 38: p. 1657-1661.2008

[25] M. Chilali, and P. Gahinet, "H-infinity Design with Pole Place Constraints: An LMI Approach". IEEE Transactions on Automatic Control. 41: p. 358-367. 1996

[26] B.J. Rhee, and S. Won, "A new fuzzy Lyapunov function approach for a Takagi-Sugeno fuzzy control system design". Fuzzy Sets and Systems, 157: p. 1211-1228. 2006.

[27] M.A. Akmal, N.F. Jamin and N.M Abdul Ghani "Fuzzy Logic Controller for two-wheeled EV3 Lego Robot "IEEE Conference on Systems, Process and Control (ICSPC 2017) Melaka, Malaysia p 134-139.2017

\section{BIOGRAPHIES OF AUTHORS}

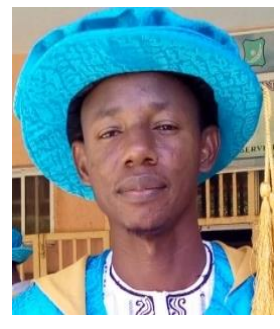

Mustapha Muhammad is currently a senior lecturer at Department of Mechatronic Engineering Bayero University, Kano, Nigeria. He received his Bachelor of Engineering and Master of Engineering degrees from Bayero University, Kano, Nigeria in January 2001 and February 2007 respectively. He received his $\mathrm{PhD}$ in Electrical Engineering (Robotics) in March 2014 from Universiti Teknologi Malaysia. His research interest includes the areas of artificial neural networks, fuzzy modeling and control, intelligent control theories and robotics.

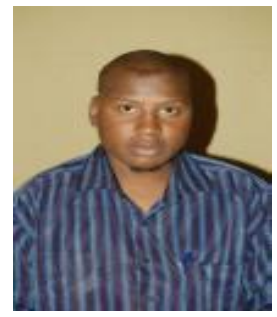

Amir Abdullahi Bature is currently a lecturer in the department of Electrical Engineering Bayero University Kano, Nigeria. His main area is control engineering and system identification. He got his $\mathrm{PhD}$ in Unversiti Teknologi Malaysia (UTM) in 2016 winning the Best Thesis award in the year. 

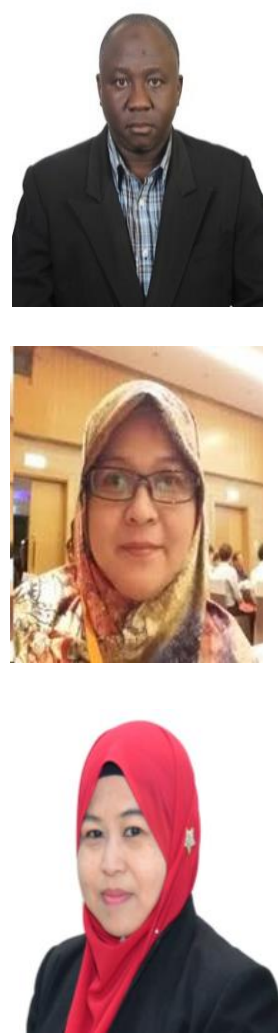

Anita Ahmad is currently a senior lecturer at the Faculty of Engineering, Universiti Teknologi Malaysia (UTM). She received the B. Eng. (1998) and the M. Eng. (2000) degrees from Universiti Teknologi Malaysia, Malaysia and the Dr. Eng. in Biomedical Engineering from the University of Leiceser in 2012 with thesis title "Dominant Frequency Estimation For Atrial Fibrillation Studies". She is mainly engaged in the research fields of atrial arrhythymias, thermoelectric energy harvester, sensors and their applications. She is a senior member of Institute of Electrical and Electronics Engineers Malaysia (IEEE) and Malaysian Simulation Society (MSS).

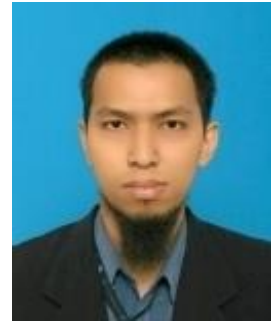
Department, School of Electrical Engineering, Faculty of Engineering, Universiti Teknologi Malaysia (UTM). He received the B. Eng. from Federal University of Technology Minna, Nigeria in the year 2002 and proceeded to University of Maiduguri, Nigeria for M. Eng. (2010). He is currently working on Mobile Robot Localization in the Mobile Robot Laboratory.

Salinda Buyamin received her B. Eng in Electrical Engineering from University of Toledo, USA in 1998, Msc in Automation and Control with Distinction from University of Newcastle, United Kingdom in 2003 and $\mathrm{PhD}$ in Control of Electrical Drives from University of Newcastle, United Kingdom in 2007. Currently, she is an Associate Professor at Universiti Teknologi Malaysia (UTM) in Control and Mechatronics Department, School of Electrical Engineering, Faculty of Engineering.Her current research interest involves the Modelling and Simulation of Dynamic Systems, Control and Development of Electric Drives System, System Identification and Estimation, Optimisation, Intelligent Control, Sensorless Control and Smart Agriculture System.

Mohamad Amir Shamsudin was born in Johor, Malaysia, in 1983. He received his $\mathrm{PhD}$ from Universiti Teknologi Malaysia (UTM) in 2015. His research interest is in Autonomous Robotics, surveillance vehicle, Nonlinear system modelling and control, and Soft computing optimization technique. 